\title{
Design of a Direct-Contact Thermal Energy Storage Heat Exchanger for the NIST Net-Zero Residential Test Facility
}

\author{
M. A. Kedzierski
}

L. Lin 


\title{
Design of a Direct-Contact Thermal Energy Storage Heat Exchanger for the NIST Net-Zero Residential Test Facility
}

\author{
M. A. Kedzierski \\ L. Lin \\ Energy and Environment Division \\ Engineering Laboratory
}

This publication is available free of charge from:

https://doi.org/10.6028/NIST.TN.2104

July 2020

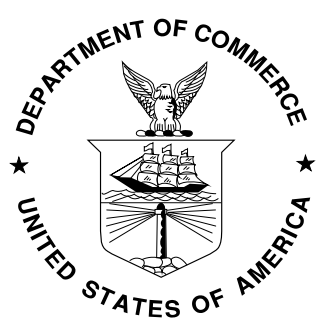

U.S. Department of Commerce Wilbur L. Ross Jr., Secretary

National Institute of Standards and Technology Walter Copan, NIST Director and Undersecretary of Commerce for Standards and Technology 
Certain commercial entities, equipment, or materials may be identified in this document in order to describe an experimental procedure or concept adequately. Such identification is not intended to imply recommendation or endorsement by the National Institute of Standards and Technology, nor is it intended to imply that the entities, materials, or equipment are necessarily the best available for the purpose.

National Institute of Standards and Technology Technical Note 2104

Natl. Inst. Stand. Technol. Tech. Note 2104, 33 pages (July 2020) CODEN: NTNOEF

This publication is available free of charge from: https://doi.org/10.6028/NIST.TN.2104 


\title{
Design of a Direct-Contact Thermal Energy Storage Heat Exchanger for the NIST Net-Zero Residential Test Facility
}

\author{
Mark. A. Kedzierski ${ }^{1}$ \\ L. Lin \\ National Institute of Standards and Technology \\ Gaithersburg, MD 20899
}

\begin{abstract}
This report describes the design of a direct-contact heat exchanger (DCHEX) to be used for thermal energy storage at the National Institute of Standards and Technology's Net-Zero Energy Residential Test Facility (NZERTF). The heat exchanger was designed for heat exchange between a phase-change material (PCM) and refrigerant. The design required the selection of a PCM that would be immiscible with the refrigerant and have a freezing point temperature of approximately of $285 \mathrm{~K}$. A key facet of the investigation was the construction of a test apparatus to observe the flow between the refrigerant and the freezing PCM to ensure a well distributed flow and one where the refrigerant could flow past the frozen PCM. The final part of the project presents a design for direct-contact heat exchange between octanoic acid (continuous phase) and the dispersed phase R410A. Twin DCHEXs were designed to house a vertical column of PCM and to distribute the refrigerant flow throughout the PCM. The height of the PCM column was determined with measurements from the literature that were re-correlated to predict the droplet heat transfer coefficient and the required height of the PCM column. A disengagement section was designed to prevent entrainment of PCM droplets into the exiting refrigerant vapor during the PCM charging. Basic equations are provided so that the design may be modified for a different PCM mass, refrigerant flow rate, temperature difference and operating fluids. An overall drawing of the DCHEX with placement of orifice holes, mist eliminator, and piping was given. The energy storage capacity of the DCHEX is approximately $191 \mathrm{MJ}$ and has the potential of providing a $33 \%$ energy savings in cooling the NZERTF.
\end{abstract}

Keywords: air conditioning, energy storage, residential

\footnotetext{
${ }^{1}$ Corresponding author. Tel./fax: (301) 975-5282/(301) 975-8973. E-mail address: Mark.Kedzierski@NIST.gov
} 


\section{TABLE OF CONTENTS}

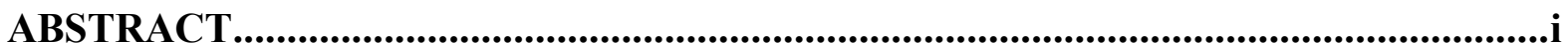

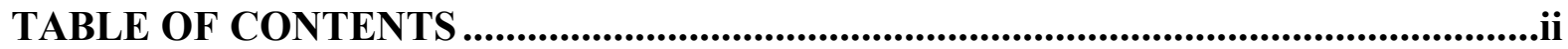

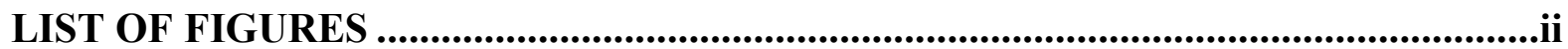

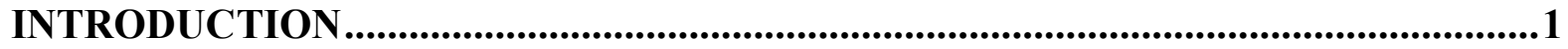

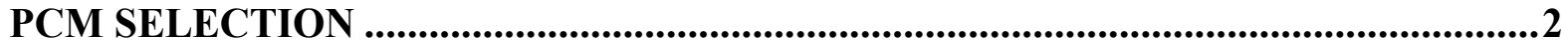

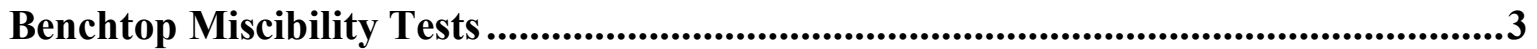

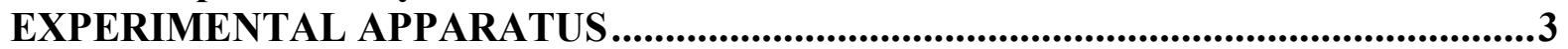

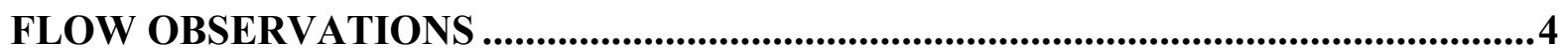

Glycerol Supercooling .......................................................................................5

DIRECT-CONTACT HEAT EXCHANGER (DCHEX) DESIGN ................................5

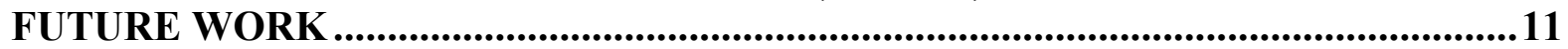

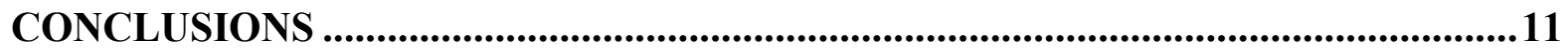

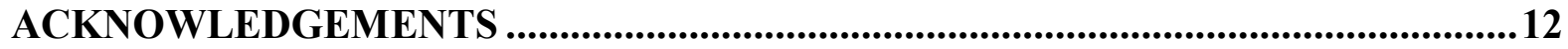

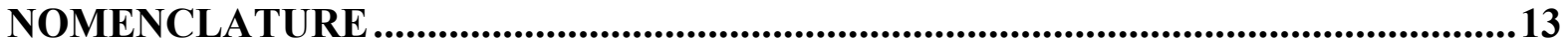

English symbols ................................................................................................. 13

Greek symbols ..................................................................................................13

Subscripts ......................................................................................................13

Abbreviations .......................................................................................................... 14

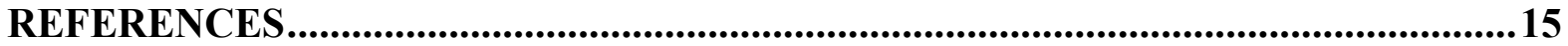

\section{LIST OF FIGURES}

Figure 1 Schematic of pressure vessel to observe miscibility.........................................16

Figure 2 Schematic and photo of PCM/refrigerant flow observation test apparatus.... 16

Figure 3 Primary flow patterns for evaporating R134a rising through glycerol..........16

Figure 4 Glycerol thermogram (Suo, 2011).................................................................16

Figure 5 Direct-contact heat exchanger designed for PCM and refrigerant .................16

Figure 6 Comparison of measured buoyancy and drag forces on a PCM droplet to gravity as a function of droplet size and terminal velocity ..............................................16

Figure 7 Required superheat for complete cyclopentane droplet evaporation for a given water depth (measurements from Smith et al. (1982)) ..........................................16

Figure 8 Refrigerant Reynolds number as a function of the number of orifices.......... 16

Figure 9 Droplet heat transfer coefficient as a function of the number of orifices........16

Figure 10 Height of PCM column in direct-contact heat exchanger..............................16

Figure 11 Diameter of direct-contact heat exchanger and a function of tank height .... 16 


\section{INTRODUCTION}

Test experience with the NIST Net-Zero Energy Residential Test Facility (NZERTF) ${ }^{2}$ shows that the air-source heat pump (ASHP) consumes approximately $40 \%$ - the largest share - of the home's total energy (Payne, 2018). Reducing its energy consumption is difficult because the Coefficient of Performance (COP) of conventional ASHPs is close to the theoretical thermodynamic limit. The COP decreases as the difference between the indoor and outdoor temperatures (i.e., the "lift" against which the ASHP works) increases (ASHRAE, 2015). The lift is directly related to the space conditioning need, therefore the heat pump to operates at a lower efficiency during the time when the building thermal load is greatest and higher efficiency when the demand is low. An analysis of the NZERTF data showed that operating the heat pump during times of the day with more favorable lift can increase the heating COP from 2.3 to 4.6 and the cooling COP from 4.3 to 5.5 (Payne, 2018). Consequently, a non-conventional ASHP that mitigates the characteristic of decreased efficiency at increased load is one approach to exceed the current state-of-the-art performance. In addition, reduced electricity needs for cooling during peak energy times and increased use at night is highly valued by the utilities.

A proposed solution for improved energy management that incorporates Phase Change Material (PCM) and Thermal Energy Storage (TES) into a residential air conditioner was modeled by Kedzierski et al. (2018). They showed that a non-conventional ASHP with improved efficiency during electrical peaks used $6 \%$ to $33 \%$ less energy than the conventional system. Some of this improvement is because the PCM provided all of the cooling needs during the peak times when air conditioning operational efficiency is low, and some improvement is due to the fact that the unit runs nearly continuously instead of cycling on and off to meet the load, thus, avoiding a typical $2 \%$ to $8 \%$ loss in efficiency due to cycling (Baxter and Moyers 1985). When the PCM provides all the cooling, the electricity requirements for air-conditioning are almost negligible. The efficiency increases because the PCM is frozen (energy is stored) when the system operates at its peak efficiency, i.e., while the outdoor temperature is low. The potential value of these savings based on electricity consumption are significant and would add to those from greater local use of $\mathrm{PV}$ and from using time-dependent electricity rates to consumers' advantage.

Kedzierski et al. (2018) were able to show that remote PCM storage integrated with a residential ASHP can provide significant energy savings and peak load shifting by generically varying the thermal resistance between the PCM and the refrigerant. In this way, it was demonstrated that the key to maximizing the efficiency of the PCM-TES ASHP was to minimize the thermal resistance between the PCM material and the refrigerant and the indoor air. It follows that the performance of TES with PCM can be dramatically improved by using direct-contact heat transfer. Directcontact heat transfer with the PCM eliminates the heat transfer resistance associated with tube walls that typically separate the PCM from the heat transfer fluid. A direct-contact heat exchanger (DCHEX) involves a heat transfer fluid flowing through and in direct contact with an immiscible solid-liquid PCM (SL-PCM). The enhanced heat transfer facilitates and significantly improves the charging/discharging process due to reduced thermal resistances. The improved heat transfer efficiency also allows the use of SL-PCMs that have relatively low thermal conductivity but high latent heat, which improves the energy storage density. In addition, the size and weight of a DCHEX is appreciably smaller than that of a conventional "indirect" heat exchanger due to the elimination of structures like tubes and fins, which also has the additional benefit of reduced

\footnotetext{
${ }^{2}$ Referred to as the "house" for brevity and clarity in much of this manuscript. See Fanney et al. (2015) for description of the house.
} 
capital, material and manufacturing costs. Because of the high energy storage density and the high heat transfer efficiency, along with the significant size and weight savings, PCM-DCHEX can facilitate light, compact, and high-performance thermal energy storage systems.

Despite the benefits associated with PCM-DCHEX, many challenges remain due to the lack of research in this area. Two main areas of interest are direct-contact heat exchange between a PCM and a single-phase fluid and between a PCM and a fluid changing phase. A major concern raised in early studies was whether the freezing PCM would block the flow of the heat transfer fluid and cause equipment failure. Even though the heat transfer fluid can flow through the channels, it may suffer a pressure drop depending on the size of the channel and how the porous structure is formed. The evolution of the path and cross-sectional flow area of passages through a freezing PCM is not well understood and requires further investigation. The existing literature mainly focuses on observations of the multiphase flow pattern and preliminary thermal storage performance measurements, leaving knowledge of the temporal melting/solidification process of a PCMDCHEX unknown. The effects of flow rate, heat transfer fluid flow pattern and thermodynamic condition (single phase or two phase), nozzle pitch and configuration, and many other factors are still unclear.

Although the structure of PCM-DCHEX is simpler, the heat transfer and fluid flow are more complex, and a temporal pressure drop prediction is not possible. Consequently, this report provides a preliminary design of a direct-contact PCM-TES DCHEX for the NZERTF airconditioner based on heat transfer and not pressure drop. The DCHEX is sized for the required air-conditioning load of the NZERTF. The refrigerant nozzle was designed to provide a well distributed flow through the PCM. A PCM with low vapor pressure and that was immiscible with R134a (and presumably R410A) was identified. Kedzierski et al. (2014) identified a remote/discrete PCM design for PCM storage with a residential ASHP. The purpose of the present investigation is to design a DCHEX for discrete PCM energy storage for use in air conditioning NIST's NZERTF. Accordingly, this paper determines the salient design parameters for an efficient and viable thermal energy storage using phase-change materials in a heat pump for net-zero homes.

\section{PCM SELECTION}

The present design is complicated by the need to have a PCM material with a very low vapor pressure, phase change at roughly $285 \mathrm{~K}$, and be immiscible with the refrigerant. Jankowski and McCluskey (2014) provide an extensive database for energy storage PCMs, including the sugar alcohol glycerol. The database includes material properties such as latent heat, density, melting temperature, specific heat, and thermal conductivity. The study does not provide physical chemistry information that could be used to estimate a PCM's miscibility with a particular fluid. Consequently, the search for a PCM that is immiscible with refrigerant is innately difficult, limited, and largely left to intuition. Refrigerants are generally nonpolar. Consequently, the search should include polar PCMs or those that behave like a polar molecule in hopes that it will not mix with a refrigerant. In addition, thermodynamic properties are primarily determined by the vapor state. Logically, if the PCM has a sufficiently low vapor pressure, its presence in the refrigerant vapor will be negligible, causing the refrigerant to behave as if the PCM wasn't present. In short, the search should begin for readily available PCMs with very low vapor pressures. Glycerol satisfies both of these conditions and it is relatively inexpensive. Glycerol mixes well with water so it acts like its polar. Its vapor pressure is $0.003 \mathrm{mmHg}\left(0.00006 \mathrm{psia}\right.$ ) at $50^{\circ} \mathrm{C}$ (Jankowski and McCluskey (2014)), which is less than the vapor pressure of many oils. 
Glycerol's melting temperature is $291.05 \mathrm{~K}$ (Jankowski and McCluskey, 2014), which is approximately $6 \mathrm{~K}$ greater than the desired melting temperature for air-conditioning applications. However, because glycerol is a sugar alcohol, it is likely to mix with other sugar alcohols that are used as PCMs to lower the melting temperature. The latent heat of melting of glycerol is $198.7 \mathrm{~kJ} / \mathrm{kg}$ (Jankowski and McCluskey, 2014), which is relatively large, thus, reducing the required mass for residential air-conditioning.

Two other PCM candidates that are likely to be immiscible with refrigerant due to their low vapor pressures and polarity are octanoic and oleic acid. These are both fatty acids. Octanoic acid melts at $289.25 \mathrm{~K}$ with a molar heat of fusion of $148.6 \mathrm{~kJ} / \mathrm{kg}$ (Hussain and Kalaiselvam, 2019). It has a vapor pressure of $0.25 \mathrm{~Pa}$ at $298 \mathrm{~K}$ (Cappa et al., 2008). Oleic acid melts at $278.55 \mathrm{~K}$ with a heat of fusion of $20.8 \mathrm{~kJ} / \mathrm{mol}$ (Inoue et al., 2004) and has a vapor pressure of $1.9 \times 10^{-6} \mathrm{~Pa}$ at $298 \mathrm{~K}$ (Cappa et al., 2008). Hussain and Kalaiselvam (2019) have studied nanoencapsulated oleic acid PCM with nanoparticles for building thermal energy storage applications. Table 1 provides selected fluid properties for oleic and octanoic, which were taken from Valeri and Meirelles (1997), Cappa et al. (2008), Hussain and Kalaiselvam (2019), and Nunes et al. (2019).

\section{Benchtop Miscibility Tests}

Glycerol was mixed with R123 in a glass jar and the mixture was observed to be completely immiscible from room temperature to approximately $260 \mathrm{~K}$. The same tests were done with an octanoic acid and R123 and the mixture was found to be miscible from room temperature to approximately $260 \mathrm{~K}$. It was hypothesized that the miscibility of R123 with the octanoic acid was due to the chlorine atom in R123.

Figure 1 shows a schematic of the test vessel that was constructed to observe a mixture of octanoic acid with R134a, which does not contain chlorine. The test vessel was designed to observe high pressure fluids up to $20 \mathrm{~atm}$. The site glass window was a commercial site glass used for airconditioning and refrigeration purposes. Copper tubing was used to connect the site glass to a refrigeration valve and to cap the lower end of the site glass. Tests with octanoic acid and R134a using the test vessel showed that the mixture was immiscible. Likewise, R134a and glycerol were observed to be immiscible.

Because of glycerol's immiscibility with both R123 and R134a, and its lower cost, it was chosen over octanoic acid for the flow observation tests. Because the melting temperature of octanoic acid was closer to the air-conditioning application than that of oleic acid, octanoic acid was chosen as the PCM for the DCHEX design.

\section{EXPERIMENTAL APPARATUS}

Figure 2 shows a sketch and picture of the experimental apparatus that was used to observe the directcontact, two-phase flow between the refrigerant and the PCM. The experimental test facility consisted of a single refrigerant loop with heat exchangers, a magnetically coupled gear pump, and a visualization section. The refrigerant flow rate, pressure, and liquid subcooling were fixed at the inlet to the test section. The chilled water flow to a brazed plate heat exchanger was used to condense refrigerant vapor and to control the amount of refrigerant subcooling delivered to the pump via a second brazed plated subcooler. Subcooled refrigerant flow was diverted to the observation test section from the pump. A combination of refrigerant bypass valve and inverter frequency variation was used to set the flowrate of subcooled refrigerant to the test section. Six instream, sheathed thermocouples in the test section were used to measure the PCM temperature. The temperature of 
the refrigerant entering the test section was measured with a thermocouple attached to the outside of the inlet refrigerant tube and covered with insulation. The refrigerant vapor exiting the test section was delivered to a brazed plate evaporator, and mixed with the subcooled refrigerant flow that bypassed the test section. The evaporator, the condenser, and the subcooler were used in concert to maintain and establish a constant pressure and to allow for subcooling. The refrigerant pressure at the exit of the test section was monitored with a dial pressure gauge.

The test section consisted of concentric, vertical tubes approximately $185 \mathrm{~mm}$ in length. The inner tube or column was made of quartz and had an inner and outer diameter of approximately $28.3 \mathrm{~mm}$ and $34.5 \mathrm{~mm}$, respectively. The inner tube contained the PCM and PTFE Raschig ring packing. Raschig rings are short cylinders generally having lengths equal to their diameters (McCabe and Smith, 1976). The Raschig rings where approximately $3 \mathrm{~mm}$ in diameter and length and filled approximately one third of the column height. The packing was held in place at the bottom of the column by a liquid refrigerant distribution plate with twenty $1 \mathrm{~mm}$ diameter orifice holes. The packing was used to promote refrigerant flow through the PCM as it froze. A plexiglass tube surrounded and was concentric with the inner quartz tube for safety. The space between the plexiglass tube and the quartz tube could be evacuated in order to reduce heat transfer to the surroundings and to prevent condensation of moist air onto the quartz tube, which would have increased heat transfer and reduced visibility. A digital video camera was used to record the direct contact heat exchange that occurred between the PCM and the refrigerant in the quartz tube.

A fixed test pressure was maintained by balancing the refrigerant duty between the subcooler, the test section, the preheater and the condensers. A magnetically coupled gear pump delivered the test refrigerant to the entrance of the test section as subcooled liquid. Further subcooling was achieved by packing the outside of the test section inlet with dry ice. This was done to reach temperatures near $260 \mathrm{~K}$. The inlet temperature of the water loop was held constant for each test with a water chilled heat exchanger where the fluid flow was varied to control the heat duty. The refrigerant flow rate was controlled by varying the pump speed using frequency inverters. The flow rate was set to evaporate all the refrigerant before it exited the PCM in the observation test section.

Figure 2 shows the location of the test section in the test rig. The inner tube of the test section was constructed of quartz and was sealed with a cylindrical insert with double o-rings at both ends. Five stainless steel sheathed thermocouples passed through the cylindrical insert and into the test section packing. This construction permitted the measurement of the PCM and the packing temperature at five different positions along the vertical test section. In addition, thermocouples were attached to the outside surface the refrigerant tube at the inlet and outlet of the test section. The test apparatus was wrapped with approximately $2 \mathrm{~cm}$ of foam insulation to minimize heat transfer between the test fluids and the ambient.

\section{FLOW OBSERVATIONS}

Figure 3 shows a sketch of the primary flow patterns that were observed for evaporating R134a rising through glycerol in the quartz column of the above test apparatus. The bubbles shown on the right side of the column contain liquid R134a, which evaporates as the bubble rises. The bubbles leave tails that trail below the bubbles and elongate as they rise due to the highly viscous nature of glycerol. For sufficiently numerous bubbles, the elongated tails of bubbles agglomerate into a vapor rivulet that forms a path for smaller bubbles. As the glycerol becomes more viscous due to cooling, the rivulets remain established and permit the flow of bubbles containing liquid to rise through it. Although the 
glycerol never completely froze, the path of the rivulets remained fixed once the glycerol reached approximately $260 \mathrm{~K}$. Consequently, the paths are likely to remain open at the freezing point because the fluid contracts upon freezing.

\section{Glycerol Supercooling}

One problem with glycerol as a PCM that was not immediately realized by the authors, is that glycerol significantly supercools before it freezes. In fact, glycerol will not freeze unless it is brought below $190 \mathrm{~K}$ and then heated to $238.7 \mathrm{~K}$ where it will freeze. The point at which glycerol freezes depends on the warming rate (Sou, 2011). Figure 4 plots differential scanning calorimetry (DSC) thermogram data from Sou (2011) that demonstrates the melting and freezing characteristics of glycerol at $0.5 \mathrm{mK} / \mathrm{s}$. In general, glycerol does not crystallize (i.e., freeze) when cooled to its melting point $(292 \mathrm{~K})$ under normal conditions, due to the strong hydrogen bond associated with the hydroxyl groups. Instead, it remains as a supercooled, highly viscous liquid until it turns into an amorphous state at the glass transition point temperature $(\sim 160 \mathrm{~K})$. The crystallization of glycerol occurs when warming up the glassy glycerol and at approximately 210 $\mathrm{K}$ to $260 \mathrm{~K}$, depending on the heating rate.

The authors tried to mitigate the supercooling and freeze the glycerol by adding zinc oxide nanoparticles without success. In fact, the supercooling of glycerol has been an unsolved problem for over a century, and glycerol has been used as an effective antifreeze additive due to the supercooling effect. The existing methods that can crystallize glycerol when cooling are based on seeding the liquid glycerol with premade glycerol crystals (Gibson and Glauque (1923) and Hass and Patterson (1941)). However, this method cannot be applied to thermal energy storage because the crystals need to be replenished between each freezing and thawing cycle. In addition, the glycerol crystallization process is slow and unstable.

\section{DIRECT-CONTACT HEAT EXCHANGER (DCHEX) DESIGN}

The general design of the DCHEX for heat exchange between a refrigerant and an immiscible PCM for use as residential energy storage is shown in Fig. 5. Liquid refrigerant flows in from the bottom of the DCHEX and up through the PCM to cool it. Conversely, when the refrigerant vapor is being cooled and condensed, the refrigerant flows downward through PCM after it enters from the top of the DCHEX and past the eliminator. The DCHEX is mainly a pressure tank with provisions to facilitate the distribution of the refrigerant flow through the PCM and to ensure that the PCM remains in the vessel. Both the 5-micron sieve placed over the lower distribution orifice plate and the upper tank screened eliminator and vapor-liquid disengagement section are designed to keep the PCM in the DCHEX. The effective diameter of the holes in the sieve $(s)$ was calculated from the surface tension $\left(\sigma_{\mathrm{p}}\right)$ forces required to hold the mass of PCM in the column height $L$ :

$$
s \leq \frac{4 \sigma_{\mathrm{p}}}{\rho_{\mathrm{p}} g L}=6.72 \times 10^{-6} \mathrm{~m}
$$

The properties of octanoic acid (shown in Table 1) were used to evaluate eq. (1). Here, the symbol for the PCM liquid density is $\rho_{\mathrm{p}}$, and that for the gravitational acceleration is $g$. The orifice plate was designed with 127 evenly spaced $0.25 \mathrm{~mm}$ diameter orifices to promote well distributed flow of refrigerant through the PCM. The orifice plate also provides structural support for the mass of PCM above it and seals at the edge of the plate where the plate and the tank meet. The orifice hole 
spacing is approximately $73 \mathrm{~mm}$ on the radius with the outermost ring of holes being approximately $17 \mathrm{~mm}$ from the edge of the plate and the first hole in the plate-center. In the PCM charging mode, the sieve will break the liquid refrigerant droplets rising from the orifice plate into micro-droplets, but due to their proximity, significant agglomeration is expected to occur. Consequently, the heat transfer performance will be between that produced by the larger droplets of the orifice plate and the smaller droplets of the sieve. Because the amount of droplet agglomeration is not easily predicted (Deepu and Baus (2014) and Sideman and Gat (1966)), the DCHEX was designed based on the orifice-plate droplet size in order to ensure there is sufficient PCM height for complete refrigerant evaporation and condensation.

The tank is filled with PCM to a level of $L$, which is a key design parameter for the DCHEX. The height of the PCM is crucial because if the DCHEX is too tall, then it will not fit between the floor and ceiling of a typical residential basement; if it is too short, then the droplets will not completely evaporate as they rise to the upper surface of the PCM. The total mass of octanoic acid as the PCM is approximately $1285 \mathrm{~kg}$, giving a storage capacity of approximately $191 \mathrm{MJ}$, which is roughly $5 \%$ larger than the required energy storage capacity of the NZERTF (Kedzierski et al., 2018). This mass fixes the PCM volume, which fixes the diameter of the tank once its height is chosen. Preliminary calculations showed that in order to keep the tank height less than the basement ceiling and the tank thickness as required by a pressure vessel within reason, the mass of PCM was split into two DCHEXs.

In the droplet evaporation mode, only saturated refrigerant vapor should exit the top of the DCHEX. Consequently, the DCHEX design should guard against the potential entrainment of the PCM into exiting refrigerant vapor. Droplet entrainment occurs when the forces that lift a droplet into the entraining flow are larger than those forces that act on it in the opposite direction of the flow. Clift et al. (1978) presented an analysis of the seven different forces on a droplet. The present analysis only considers the buoyant force $\left(F_{\mathrm{b}}=\rho_{\mathrm{rv}} D_{\mathrm{p}}^{3} g \pi / 6\right)$ and the drag force ( $\left.F_{\mathrm{d}}=C_{\mathrm{d}} \rho_{\mathrm{rv}} D_{\mathrm{p}}^{2} u_{\mathrm{rv}}^{2} \pi / 8\right)$ that act to entrain the droplet and the gravity force $\left(F_{\mathrm{g}}=\rho_{\mathrm{p}} D_{\mathrm{p}}^{3} g \pi / 6\right)$ that acts to keep the PCM with its bulk mass. The velocity of the refrigerant vapor above the PCM is $u_{\mathrm{rv}}$. If the ratio of the sum of the buoyance and drag force to the gravity force is sufficiently less than 1 , then it is likely that droplet entrainment will not occur. This ratio can be expressed in terms of fluid properties while using the expressions for the various forces that are given by Clift et al. (1978):

$$
\frac{F_{\mathrm{b}}+F_{\mathrm{d}}}{F_{\mathrm{g}}}=\frac{\rho_{\mathrm{rv}}}{\rho_{\mathrm{p}}}+\frac{12 C_{\mathrm{d}} \dot{m}_{\mathrm{r}}^{2}}{\pi^{2} D_{\mathrm{p}} D_{\mathrm{t}}^{4} \rho_{\mathrm{p}} \rho_{\mathrm{rv}} g}<1
$$

The density of the refrigerant vapor above the PCM and its total mass flowrate are $\rho_{\mathrm{rv}}$ and $\dot{m}_{\mathrm{r}}$, respectively. The drag coefficient $\left(C_{\mathrm{d}}\right)$ for spherical particles was taken from Clift et al. (1978):

$$
C_{\mathrm{d}}=\frac{24}{\operatorname{Re}_{\mathrm{p}}}\left[1+0.1315 \mathrm{Re}_{\mathrm{p}}^{0.82-0.05 \ln \left(\mathrm{Re}_{\mathrm{p}}\right)}\right]
$$

The Reynolds number for the PCM particle $\left(\mathrm{Re}_{\mathrm{p}}\right)$ was calculated as: 


$$
\operatorname{Re}_{\mathrm{p}}=\frac{4 \dot{m}_{\mathrm{r}} D_{\mathrm{p}}}{\pi \mu_{\mathrm{rv}} D_{\mathrm{t}}^{2}}
$$

where $\mu_{\mathrm{rv}}$ is the dynamic viscosity of the refrigerant vapor. The values of $\operatorname{Re}_{\mathrm{p}}$ were between 1.2 and 2.5, which is within the range that eq. (3) is valid.

Figure 6 plots eq. (2) as a function of the PCM particle diameter $\left(D_{\mathrm{p}}\right)$. Figure 6 was made while using a PCM heat exchanger tank $\left(D_{\mathrm{t}}\right)$ diameter of $0.91 \mathrm{~m}$ and a refrigerant flow rate of $0.018 \mathrm{~kg} \cdot \mathrm{s}^{-}$ ${ }^{1}$, which is half the expected flow rate of the NZERTF ASHP (Kedzierski et al., 2018). Figure 6 shows that, for PCM droplets with diameters between $0.3 \mathrm{~mm}$ and $0.6 \mathrm{~mm}$, the lifting forces on the droplet are always less than $5 \%$ of the gravity force. Consequently, PCM droplet entrainment should not occur for the given refrigerant mass flowrate and PCM tank diameter. A simple estimate for the minimum vapor-liquid disengagement height $\left(H_{\mathrm{D}}\right)$ to reduce droplet entrainment when it is expected to occur and when an eliminator is not used is given by GPSA (2004):

$$
H_{\mathrm{D}}=\frac{u_{\mathrm{rv}}}{u_{\mathrm{T}}} D_{\mathrm{t}}
$$

Equating the $F_{\mathrm{g}}$ to the sum of $F_{\mathrm{b}}$ and $F_{\mathrm{d}}$, and solving for the droplet velocity yields the terminal velocity of the droplet $\left(u_{\mathrm{T}}\right)$ :

$$
u_{\mathrm{T}}=\sqrt{\frac{4\left(\rho_{\mathrm{p}}-\rho_{\mathrm{rv}}\right) D_{\mathrm{p}} g}{3 C_{\mathrm{d}} \rho_{\mathrm{rv}}}}
$$

Although eq. (5) is conveniently simple, the origin of its derivation is not easily discerned. The $u_{\mathrm{T}}$ is the maximum velocity that a PCM droplet would obtain if it were to be dropped into an atmosphere of refrigerant vapor and allowed to fall long enough to achieve zero acceleration. It is not obvious why eq. (5) gives one diameter for $H_{\mathrm{D}}$ when the vapor velocity is just large enough to keep a droplet from falling. Nevertheless, eq. (5) is an accepted methodology of GPSA (2004) and eq. (5) predicts a small $H_{\mathrm{D}}$ (as shown below), which is consistent with the lift forces on the droplet being less than $5 \%$ of the gravity force.

Figure 6 plots $u_{\mathrm{T}}$ as a function of potential droplet sizes. For fixed value of $u_{\mathrm{rv}}(0.0068 \mathrm{~m} / \mathrm{s})$, the $u_{\mathrm{rv}} / u_{\mathrm{T}}$ varies between roughly 0.008 and 0.015 . According to eq. (5), this corresponds to an $H_{\mathrm{D}}$ roughly between $7 \mathrm{~mm}$ and $14 \mathrm{~mm}$. Figure 5 shows that the dome height of the semi-spherical end of the tank is approximately $0.38 D_{\mathrm{t}}$ or $0.34 \mathrm{~m}$, which exceeds the GPSA (2004) recommended $H_{\mathrm{D}}$ in eq. (5) by at least $0.32 \mathrm{~m}$. Although the dome provides a sufficient $H_{\mathrm{D}}$, an additional disengagement height of $0.12 D_{\mathrm{t}}(0.11 \mathrm{~m})$ was added directly above the PCM surface to provide space between the PCM and the eliminator. Combining the two heights gives the space above and below the screen eliminator as $0.5 D_{\mathrm{t}}$. Together, the screen eliminator and the disengagement height of $0.5 D_{\mathrm{t}}$ ensures that no entrainment of PCM in the refrigerant vapor flow is likely to occur. Considering the height necessary for the above components, the entrance and exit ports and supporting legs, the allowable height for the PCM column is less than $1.2 \mathrm{~m}$. 
The DCHEX was designed based on the refrigerant evaporation mode because the refrigerant evaporation mode will have a similar, but a slightly larger, required PCM column height than the refrigerant condensation mode for complete phase change. The heat transfer between a droplet rising and evaporating within a column of liquid needs to be quantified to calculate the PCM column height for complete evaporation. Smith et al. (1982) determined a droplet heat transfer coefficient $\left(h_{\mathrm{d}}\right)$ from an explicit solution for evaporating droplets rising through a stagnant continuous phase. The droplet heat transfer coefficient was expressed in terms of a droplet Nusselt number $\left(\mathrm{Nu}_{\mathrm{d}}\right)$ with the traditional relationship between heat and mass transfer (Incropera and DeWitt, 2002):

$$
\mathrm{Nu}_{\mathrm{d}}=\frac{h_{\mathrm{d}} D_{\mathrm{d}}}{k_{\mathrm{c}}}=\gamma \operatorname{Re}_{\mathrm{c}}^{\mathrm{x}} \operatorname{Pr}_{\mathrm{c}}^{1 / 3}
$$

Here $D_{\mathrm{d}}$ is the diameter of the dispersed phase droplet, which increases by producing vapor as it rises through the continuous phase from the all-liquid $D_{\text {do }}$ at the orifice plate exit to the all-vapor diameter $D_{\mathrm{do}}\left(\rho_{\mathrm{dl}} / \rho_{\mathrm{dv}}\right)^{1 / 3}$ at the top of the PCM column. The expression for the all-vapor diameter assumes that agglomeration with other droplet/bubbles does not occur. The $\rho_{\mathrm{dl}}$ and the $\rho_{\mathrm{dv}}$ are the liquid and vapor densities of the dispersed phase, respectively. In their experiment, Smith et al. (1982) used $0.5 \mathrm{~mm}$ diameter orifice holes that produced an initial droplet diameter $\left(D_{\mathrm{do}}\right)$ of $1.0 \mathrm{~mm}$. They verified the value of $D_{\mathrm{do}}$ with photographic observations. The present orifice plate design uses $0.25 \mathrm{~mm}$ diameter orifices and, following what was observed by Smith et al. (1982), assumes that the $D_{\text {do }}$ is twice that value, i.e., $0.5 \mathrm{~mm}$. The $k_{\mathrm{c}}$, the $\operatorname{Re}_{\mathrm{c}}$, and the $\operatorname{Pr}_{\mathrm{c}}$ are the thermal conductivity, the Reynolds number, and the Prandtl number of the continuous phase, respectively.

Smith et al. (1982) included eq. (7) as part of an explicit derivation for the required height of continuous phase liquid $(L)$ to just completely evaporate rising droplets from saturated liquid to saturated vapor for a given superheat $(\Delta T)$. The superheat was defined as the temperature difference between the saturated dispersed phase and the uniform temperature of the stagnate continuous phase. The Smith et al. (1982) expression for $L$ and $\Delta T$ is based on properties of the dispersed and continuous phases:

$$
\left(\frac{\rho_{\mathrm{dl}}}{\rho_{\mathrm{dv}}}\right)^{\frac{2-x}{3}}-1=2\left(\frac{\rho_{\mathrm{c}} k_{\mathrm{c}}}{\rho_{\mathrm{dv}} \mu_{\mathrm{c}} \lambda_{\mathrm{d}} D_{\mathrm{do}}}\right)(2-\mathrm{x}) \gamma \operatorname{Re}_{\mathrm{co}}^{\mathrm{x}-1} \operatorname{Pr}_{\mathrm{c}}^{1 / 3} L \Delta T
$$

where $\rho_{\mathrm{c}}, \mu_{\mathrm{c}}, \lambda_{\mathrm{d}}$, are the liquid density and viscosity of the continuous phase and the latent heat of the dispersed phase, respectively. The continuous phase Reynolds number at the orifice plate exit $\left(\operatorname{Re}_{\mathrm{co}}\right)$ is:

$$
\operatorname{Re}_{\mathrm{co}}=\frac{4 \rho_{\mathrm{c}} \dot{m}_{\mathrm{d}} D_{\mathrm{do}}}{\pi \rho_{\mathrm{dl}} \mu_{\mathrm{c}} D_{\mathrm{or}}^{2} N_{\mathrm{or}}}=\frac{4 \rho_{\mathrm{p}} \dot{m}_{\mathrm{r}} D_{\mathrm{do}}}{\pi \rho_{\mathrm{rl}} \mu_{\mathrm{p}} D_{\mathrm{or}}^{2} N_{\mathrm{or}}}
$$

The total dispersed mass flowrate $\left(\dot{m}_{\mathrm{d}}\right)$, the diameter of the orifice $\left(D_{\mathrm{or}}\right)$, and the number of orifices $\left(N_{\text {or }}\right)$ were used to calculate the initial velocity of the exiting droplet. The $\mathrm{Re}_{\mathrm{co}}$ is based on the 
initial droplet diameter $\left(D_{\mathrm{do}}\right)$. The rightmost side of eq. (9) expresses $\mathrm{Re}_{\mathrm{co}}$ in terms of the PCM and refrigerant properties, where the PCM and the refrigerant are the continuous and the dispersed phase, respectively.

Figure 7 shows the heat transfer measurements that Smith et al. (1982) made to determine the leading constant- $\gamma$ and the exponent-x in eqs. (7) and (8). The measured superheat between the dispersed phase, cyclopentane, and the continuous phase (water) is plotted against the height of water required for complete evaporation. The circles and squares represent measurements for $\mathrm{Re}_{\mathrm{co}}$ of 8880 and 13324, respectively. The first data set $\left(\operatorname{Re}_{\mathrm{co}}=8880\right)$ had 7 orifice holes spaced at 100 orifice diameters, while the second $\left(\operatorname{Re}_{\mathrm{co}}=13324\right)$ were done for 19 orifice holes spaced at 58 orifice diameters. The $\operatorname{Re}_{\mathrm{co}}$ was calculated with an orifice diameter $\left(D_{\mathrm{or}}\right)$ of $0.5 \mathrm{~mm}$ and the $D_{\mathrm{do}}$ that was observed by Smith et al. (1982) in their experiments: $1 \mathrm{~mm}$. For a fixed $L$, Smith et al. (1982) determined the required superheat for complete evaporation by reducing the superheat until cyclopentane began to appear as a layer on top of the water. From these measurements, Smith et al. (1982) provided 24 different regression constant sets for $\gamma$ and $\mathrm{x}$. For a given Re, the 24 sets of constants can produce greater than two orders of magnitude variation in the droplet heat transfer coefficient. Obviously, the provided constants cannot be used to design a DCHEX because it is not known which constants are valid. Consequently, the Smith et al. (1982) measurements were re-regressed in this study to provide a single value for $\gamma$ and $\mathrm{x}$ for the observed droplet diameter of $1 \mathrm{~mm}$. The single fit $(\gamma=0.020 \pm 0.002 \text { and } \mathrm{x}=0.728 \pm 0.008)^{3}$ is shown to predict approximately $77 \%$ of the required continuous phase heights to within $0.14 \mathrm{~mm}$ for both Reynolds numbers as shown by the solid and dashed lines in Fig. 7.

Justification for disregarding the fitting solutions of Smith et al. (1982) is mainly that their fits were obtained without varying the $\mathrm{Re}_{\mathrm{co}}$. This flawed methodology effectively treats the solution for the Re-exponent as a constant multiplier on $\gamma$. Statistical analysis requires that a parameter must be varied in order to determine its dependence on the data. In other words, the Re must be varied in order to regress the exponent on Re. Smith et al. (1982) did not do this. Instead, they regressed the two data sets for different Re as separate data sets, thus, losing the influence of Re. The fit provided here regresses the two data sets for the two different Re together in order to fit the value of $\mathrm{x}$. The reason that Smith et al. (1982) gave for separating the data into two separate sets is that they claimed that the droplets agglomerated in one data set and not in the other. They provided no evidence for agglomeration or lack of agglomeration except for a flawed argument that the void fraction was larger for the larger Re data set. The void fraction was greater because, for a fixed continuous-phase mass, when the dispersed phase mass flowrate is increased via increased Re, by definition, the void fraction must increase. For the Smith et al. (1982) experimental configuration, the void fraction increased for increased Re independent of droplet/bubble agglomeration. Further justification for ignoring the claimed effect of agglomeration is that the Smith et al. (1982) derived solution for agglomeration differs mainly from their preagglomeration derivation by the exponent on the droplet velocity, which contains the exponent-x. If the derivation distinguishes between agglomeration and preagglomeration stages with a different exponent, but the present regression fits both data sets well with a single exponent, then this suggests that agglomeration is not significant. Finally, it is not clear how 19

\footnotetext{
${ }^{3}$ Uncertainties are for a $95 \%$ confidence level.
} 
orifice holes, with a spacing that is 58 orifice diameters, will produce significantly more agglomeration than 7 orifice holes with a spacing that is 100 orifice diameters.

Figure 8 plots the refrigerant droplet Reynolds number evaluated at the nozzle $\left(\operatorname{Re}_{\mathrm{co}}\right)$, given in eq. (3), as a function of the number of orifice holes. The Reynolds number is based on half of the refrigerant mass flow because it is divided between two identical DCHEXs. As will be illustrated, the $0.25 \mathrm{~mm}$ orifice diameter was chosen as a compromise to limit the height of the DCHEX by maintaining larger droplet heat transfer coefficients. For between ten and 150 orifice holes, the boundary layer on the spherical droplet is laminar because the Reynolds number is always less than $2 \times 10^{5}$ (Incropera and DeWitt, 2002). Smaller Reynolds numbers will lead to smaller droplet heat transfer coefficients according to eq. (7) and shown in Fig. 9. Figure 9 shows that the heat transfer coefficient varies by approximately $222 \%$ from 50 to 10 orifice holes. While $h_{\mathrm{d}}$ changes by approximately $55 \%$ from 50 to 150 orifice holes. Obviously, the droplet heat transfer is more sensitive to the number of orifice holes choice for designs with less than 50 orifice holes than it is for designs with more than 50 orifice holes.

Figure 10 shows the height $(L)$ of the PCM column required to completely evaporate an all-liquid refrigerant drop to saturated vapor. Equation (8) was used to solve for $L$ while using the properties of the refrigerant and the PCM that are given in Table 1 . In addition, a superheat of $8 \mathrm{~K}$, a total refrigerant flowrate of $0.018 \mathrm{~kg} / \mathrm{s}$, and the regression constants as determined in the present analysis $(\gamma=0.02$ and $\mathrm{x}=0.728)$ were used. Results for three different orifice diameters are shown. The solid line shows the predictions using an orifice diameter and the droplet diameter of $0.25 \mathrm{~mm}$ and $0.50 \mathrm{~mm}$, respectively. Two dashed lines above and below the solid line show predictions using orifice diameters of $0.50 \mathrm{~mm}$ and $0.10 \mathrm{~mm}$, respectively. In general, Fig. 10 shows that the required PCM column height decreases as the number of orifice holes increases and as the orifice diameter decreases. If maximizing the droplet heat transfer shown in Fig. 9 was the only design consideration, then the DCHEX would be designed with 10 orifice holes or less and with the $0.5 \mathrm{~mm}$ orifice diameter. As Fig. 10 shows, the design that uses ten $0.5 \mathrm{~mm}$ diameter orifice holes requires a PCM height of nearly $2.2 \mathrm{~m}$, which closely approaches the ceiling height of most residential basements. To remain within the vertical space limitations of most residential basements, the PCM column height $(L)$ must reside within the shaded region of Fig. 10. i.e. $L<$ $1.2 \mathrm{~m}$. Consequently, a design using $0.50 \mathrm{~mm}$ diameter orifice holes is not possible if $N_{\text {or }}$ is to be limited to 150 because all required PCM heights are greater than $1.2 \mathrm{~m}$. Conversely, Fig. 10 shows that all of the designs using the $0.10 \mathrm{~mm}$ diameter orifice holes result in acceptable PCM column heights. However, it was felt that the $0.10 \mathrm{~mm}$ orifice was more likely to be out of the range of validity for the droplet heat transfer correlation than the predictions for the $0.25 \mathrm{~mm}$ diameter design. For this reason, the $0.25 \mathrm{~mm}$ orifice hole design was chosen near the allowable limit for $L$. This design gave 127 orifice holes $(0.25 \mathrm{~mm}$ diameter $)$ and a column height of $1.08 \mathrm{~m}$.

Figure 11 shows that, given the constraint of fixed PCM mass, the required diameter of the heat exchanger $\left(D_{\mathrm{t}}\right)$ is $0.91 \mathrm{~m}$ for $L=1.2 \mathrm{~m}$. Spotts et al. (2004) give the pressure vessel wall thickness $(t)$ necessary to resist a yield stress $(S)$ due to a design pressure $(P)$ :

$$
t=\frac{P D_{\mathrm{t}} / 2}{S-0.6 P}+t_{\mathrm{c}}=13 \mathrm{~mm}+2 \mathrm{~mm}=15 \mathrm{~mm}
$$


The allowed yield stress used in eq. (10) for A-106-GR.B steel was $175.2 \mathrm{~N} / \mathrm{mm}^{2}$ (Spotts et al., 2004). The $t_{\mathrm{c}}$ is the thickness to allow for corrosion of the steel over time. A design pressure of 5 $\mathrm{MPa}$ was used considering that the pressure of R410A should always remain less than $4 \mathrm{MPa}$ (Prah, 2001). Considering the length, diameter and thickness, end caps, the mass of each heat exchanger without PCM is approximately $400 \mathrm{~kg}$. The mass of each DCHEX, including the PCM, is approximately $1043 \mathrm{~kg}$. The total mass of each DCHEX will be slightly larger than $1043 \mathrm{~kg}$ when the mass of the ancillary equipment, such as support legs, piping, and orifice plate, is included.

\section{FUTURE WORK}

An accurate transient pressure drop model needs to be developed for a dispersed phase flowing through a continuous freezing phase. In addition, the Smith et al. (1982) model needs to be improved with more data for more fluids, operating conditions, and orifice diameters. This will allow the optimization of the DCHEX for maximum heat transfer and minimum pressure drop. In general, comprehensive investigations are needed to understand the fundamentals and to develop simulation tools that can be used to design PCM-DCHEXs for different thermal energy applications. This would involve the search for new PCMs. Machine-learning-assisted screening could be an efficient tool to search for optimal phase change materials to be used for energy storage. Finally, the heat exchanger designed here needs to be constructed, installed and tested in the NZERTF.

\section{CONCLUSIONS}

A viable thermal energy storage (TES) design for a residential air-conditioner hinges on reducing the thermal resistances associated with charging and discharging phase change material (PCM). Direct contact heat exchange between the PCM and the heat-pump refrigerant of is one approach toward significantly reducing thermal resistances and improving the efficiency of residential TES. Direct-contact heat exchange eliminates physical barriers that significantly contribute to the heat transfer resistance between the refrigerant and the PCM. As a necessary step prior to testing residential TES, a direct-contact heat exchanger was designed and sized for the National Institute of Standards and Technology's Net-Zero Energy Residential Test Facility (NZERTF).

A visualization test apparatus was constructed to observe the flow of refrigerant through the PCM. Glycerol was used as the PCM because of its immiscibility with R134a and its relatively low cost. R134a was used as the refrigerant for its significantly lower vapor pressure as compared to R410A, which would keep the operating pressure well below the burst limit of the quartz observation test section. The tests verified that refrigerant continues to flow through the PCM as it freezes without producing a total blockage of flow.

For the heat exchanger design, octanoic acid was chosen as the PCM and R410A as the refrigerant because these fluids are immiscible with each other and less likely to supercool. Twin heat exchangers were designed to house a vertical column of PCM and to distribute the refrigerant flow throughout the PCM. A key design parameter was the height of the PCM column. The PCM height had to be tall enough to completely evaporate a liquid refrigerant droplet and short enough to fit within the vertical space limitations of a typical residential basement. This height was found to be $1.2 \mathrm{~m}$, which fixed the diameter at $0.91 \mathrm{~m}$. The mass of each heat exchanger is approximately $1043 \mathrm{~kg}$. Measurements from the literature were re-correlated to predict the droplet heat transfer coefficient and the required height of the PCM column. A disengagement section was designed to prevent entrainment of PCM droplets into the exiting refrigerant vapor during the PCM 
charging. Basic equations are provided so that the design may be modified for different a PCM mass, refrigerant flow rate, temperature difference and operating fluids. An overall drawing of the heat exchanger with placement of orifice holes is given. The energy storage capacity of the DCHEX is approximately $191 \mathrm{MJ}$ and has the potential of providing a $33 \%$ energy savings in cooling the NZERTF.

\section{ACKNOWLEDGEMENTS}

This work was funded by NIST Exploratory Research Project. Thanks go to Dr. Riccardo Brignoli and to Dr. W. Vance Payne of NIST for their constructive criticism of the draft manuscript. 


\section{NOMENCLATURE}

English symbols

$c_{\mathrm{p}} \quad$ specific heat $\left(\mathrm{kJ} \cdot \mathrm{kg}^{-1} \cdot \mathrm{K}^{-1}\right)$

$C_{\mathrm{d}} \quad$ drag coefficient (-)

$D$ diameter (m)

$F_{\text {b }} \quad$ buoyance force $(\mathrm{N})$

$F_{\text {d }} \quad$ drag force $(\mathrm{N})$

$F_{\mathrm{g}} \quad$ gravity force $(\mathrm{N})$

$g \quad$ gravitational acceleration constant $\left(\mathrm{m} \cdot \mathrm{s}^{-2}\right)$

$h_{\mathrm{d}} \quad$ droplet heat transfer coefficient $\left(\mathrm{W} \cdot \mathrm{m}^{-2} \cdot \mathrm{K}^{-1}\right)$

$H_{\mathrm{D}} \quad$ disengagement height (m)

$i_{\mathrm{fg}} \quad$ latent heat of vaporization $\left(\mathrm{kJ} \cdot \mathrm{kg}^{-1}\right)$

$i_{\mathrm{fs}} \quad$ heat of fusion $\left(\mathrm{kJ} \cdot \mathrm{kg}^{-1}\right)$

$k \quad$ thermal conductivity $\left(\mathrm{W} \cdot \mathrm{m}^{-1} \cdot \mathrm{K}^{-1}\right)$

$L \quad$ height of PCM column (m)

$M \quad \operatorname{mass}(\mathrm{kg})$

$\dot{m} \quad$ mass flow rate $\left(\mathrm{kg} \cdot \mathrm{s}^{-1}\right)$

$N_{\text {or }} \quad$ number of orifices (-)

$P \quad$ pressure $(\mathrm{Pa})$

$\mathrm{Pr}_{\mathrm{c}} \quad$ Prantdl number of continuous phase (-)

Re Reynolds number (-)

$s \quad$ effective sieve hole diameter (m)

$S \quad$ yield stress $\left(\mathrm{N} \cdot \mathrm{m}^{-2}\right)$

$t \quad$ thickness of tank wall (m)

$t_{\mathrm{c}} \quad$ corrosion thickness $(\mathrm{m})$

$T$ temperature $(\mathrm{K})$

$u \quad$ velocity $\left(\mathrm{m} \cdot \mathrm{s}^{-1}\right)$

$u_{\mathrm{T}} \quad$ terminal velocity $\left(\mathrm{m} \cdot \mathrm{s}^{-1}\right)$

$V \quad$ voltage (V)

$\mathrm{X} \quad$ dimensionless fitted exponent in eqs. (7) and (8)

Greek symbols

$\Delta T \quad$ temperature difference between continuous and dispersed phases $(\mathrm{K})$

$\gamma \quad$ dimensionless fitted constant in eqs. (7) and (8)

$\lambda_{\mathrm{p}} \quad$ latent heat of melting $\left(\mathrm{J} \cdot \mathrm{kg}^{-1}\right)$

$\mu \quad$ dynamic viscosity $\left(\mathrm{kg} \cdot \mathrm{m}^{-1} \cdot \mathrm{s}^{-1}\right)$

$\rho \quad$ density $\left(\mathrm{kg} \cdot \mathrm{m}^{-3}\right)$

$\sigma \quad$ surface tension $\left(\mathrm{N} \cdot \mathrm{m}^{-1}\right)$

\section{$\underline{\text { Subscripts }}$}

c continuous phase

co continuous phase evaluated at orifice

d dispersed phase or droplet

do droplet at orifice

dl dispersed phase liquid 


$$
\begin{array}{ll}
\mathrm{dv} & \text { dispersed phase vapor } \\
\mathrm{l} & \text { liquid } \\
\mathrm{m} & \text { melting } \\
\mathrm{p} & \text { phase change material } \\
\mathrm{rl} & \text { refrigerant liquid } \\
\mathrm{rv} & \text { refrigerant vapor } \\
\mathrm{t} & \text { heat exchanger tank } \\
\mathrm{v} & \text { vapor }
\end{array}
$$

\begin{tabular}{|c|c|}
\hline & \\
\hline$\overline{\mathrm{ASHP}}$ & Air-Source Heat Pump \\
\hline $\mathrm{COP}$ & Coefficient of Performance \\
\hline $\mathrm{DC}$ & Direct Contact \\
\hline DCHEX & Direct-Contact Heat Exchanger \\
\hline $\mathrm{DSC}$ & Differential Scanning Calorimetry \\
\hline NIST & National Institute of Standards and Technology (in U.S. Dept. of Commerce) \\
\hline NZERTF & Net-Zero Energy Residential Test Facility at NIST \\
\hline PCM & Phase Change Material \\
\hline TES & Thermal Energy Storage \\
\hline U.S. & United States \\
\hline
\end{tabular}




\section{REFERENCES}

ASHRAE. 2015. 2015 ASHRAE Handbook -HVAC Systems and Equipment, Chapter 51, Atlanta, GA, p. 51-1.

Baxter, V.D., and Moyers, J.C. 1985. Field-measured cycling, frosting, and defrosting losses for a high-efficiency air-source heat pump. ASHRAE Trans. Vol. 91:2B. 537-554.

Cappa, C.D., Lovejoy, E.R., Ravishankara, A.R. 2008. Evaporation rates and vapor pressures of the even-numbered C 8-C18 monocarboxylic acids. J. Phys. Chem. A 112, 3959-3964. https://doi.org/10.1021/jp710586m

Clift, R., Grace, J.R.,Weber, M.E. 1978. Bubbles, Drops, and Particles, Academic Press, New York, NY.

Deepu, P., Basu, S., 2014. Effect of evaporation and agglomeration on droplet shape oscillations. Chem. Eng. Sci. 119, 212-217. https://doi.org/10.1016/j.ces.2014.08.033

Fanney, A. H., Payne, V., Ullah, T., Ng, L., Boyd, M., Omar, F., Davis, M., Skye, H., Dougherty, B., Polidoro, B., Healy, W., Pettit, E., 2015. Net-zero and beyond! Design and performance of NIST's net-zero energy residential test facility, Energy and Buildings, 101, 95109. http://dx.doi.org/10.1016/j.enbuild.2015.05.002

Gibson, G.K., Glauque, W.P. 1923. The third law of thermodynamics. Evidence from the specific heats of glycerol that the entropy of A glass exceeds that of a crystal at the absolute zero, J. Am. Chem. Soc. 45 93-104. doi:10.1021/ja01654a014.

GPSA. 2004. Engineering Data Book, Gas Processors Suppliers Association (GPSA), $12^{\text {th }}$ ed, Tulsa, OK, p. 7-11.

Hass, H.B., Patterson, J.A. 1941. Purification of Glycerol by Crystallization, Ind. Eng. Chem. 33 615-616. doi:10.1021/ie50377a015.

Hussain, S. I., and Kalaiselvam, S. 2019. Nanoencapsulation of oleic acid phase change material with Ag2O nanoparticles-based urea formaldehyde shell for building thermal energy storage, Journal of Thermal Analysis and Calorimetry https://doi.org/10.1007/s10973-019-087325(0123456789().,-volV)(0123456789,-().volV)

Incropera, F. P., and DeWitt, D. P. 2002. Fundamentals of Heat and Mass Transfer, 5th ed., John Wiley \& Sons, New York.

Inoue, T., Hisatsugu, Y., Suzuki, M., Wang, Z.N., Zheng, L.Q. 2004. Solid-liquid phase behavior of binary fatty acid mixtures: 3 . Mixtures of oleic acid with capric acid (decanoic acid) and caprylic acid (octanoic acid). Chem. Phys. Lipids 132, 225-234. https://doi.org/10.1016/j.chemphyslip.2004.07.004 
Jankowski, N.R., McCluskey, F.P., 2014. A review of phase change materials for vehicle component thermal buffering. Appl. Energy 113, 1525-1561.

https://doi.org/10.1016/j.apenergy.2013.08.026

Kedzierski, M. A., Payne, W. V., and Skye, H. M. 2018. Thermal Energy Storage for the NIST Net-Zero House Heat Pump, NIST Technical Note 2005, U.S. Department of Commerce, Washington, D.C.

Kedzierski, M. A., Payne, W. V., and Skye, H. M. 2014. Potential Research Areas in Residential Energy Storage for NIST's Engineering Laboratory, NIST Technical Note 1844, U.S.

Department of Commerce, Washington, D.C.

Lemmon, E. W., Bell, I. H., Huber, M. L., and McLinden, M. O. 2018. NIST Standard Reference Database 23 (REFPROP), Version 10., National Institute of Standards and Technology, Boulder, CO.

McCabe, W. L., and Smith, J. C. 1976. Unit Operations of Chemical Engineering, $3^{\text {rd }}$ ed., McGraw-Hill, pp. 709-710.

Nunes, R.J., Saramago, B., Marrucho, I.M. 2019. Surface Tension of dl -Menthol:Octanoic Acid Eutectic Mixtures. J. Chem. Eng. Data 64, 4915-4923. https://doi.org/10.1021/acs.jced.9b00424

Payne, W. V. 2018. Private Communications. The National Institute of Standards and Technology, U.S. Department of Commerce, Washington, D.C.

Prah, F. 2001. Refrigerant 410A, Refrigeration Service Engineers Society, Des Plaines, Illinois, 620-108 Section 3, https://www.rses.org/assets/r410a/R-410A.PDF

Sideman, S., Gat, Y. 1966. Direct contact heat transfer with change of phase: Spray-column studies of a three-phase heat exchanger. AIChE J. 12, 296-303.

https://doi.org/10.1002/aic.690120217

Smith, R.C., Rohsenow, W.M., Kazimi, M.S. 1982. Volumetric Heat-Transfer Coefficients for Direct-Contact Evaporation. J. Heat Transfer 104, 264-270. https://doi.org/10.1115/1.3245082

Sou, K. 2011. High-resolution Calorimetry on Thermal Behavior of Glycerol (Evolution of Personal Desk Lab (PDL) System to a Research Use). Ph.D. Thesis, Chiba University, Chiba, Japan.

Spotts, M.F., Shoup, T.E., Hornberger, L.E. 2004. Design of Machine Elements, Prentice Hall. $8^{\text {th }}$ ed.

Valeri, D., Meirelles, A.J.A. 1997. Viscosities of fatty acids, triglycerides, and their binary mixtures. JAOCS, J. Am. Oil Chem. Soc. 74, 1221-1226. https://doi.org/10.1007/s11746-9970048-6 
Table 1 Selected fluid properties of PCMs and R410A at or near $T_{\mathrm{v}}$ or $T_{\mathrm{m}}$

\begin{tabular}{|c|c|c|c|c|c|c|c|c|c|c|}
\hline Fluid & $\begin{array}{c}T_{\mathrm{V} \text { OR }} \\
T_{\mathrm{m}} \\
(\mathrm{K})\end{array}$ & $\begin{array}{c}P_{\mathrm{v}} \\
(\mathrm{kPa})\end{array}$ & $\begin{array}{l}\operatorname{Pr}_{v} \\
(-)\end{array}$ & $\begin{array}{c}k_{\mathrm{l}} \\
\left(\mathrm{mWm}-\mathrm{m}^{-1} \mathrm{~K}^{-1}\right)\end{array}$ & $\begin{array}{c}\mu \mathrm{l} \\
\left(\mu \mathrm{kg} \cdot \mathrm{m}^{-1} \cdot \mathrm{s}^{-1}\right)\end{array}$ & $\begin{array}{c}\sigma \\
\left(\mathrm{N} \cdot \mathrm{m}^{-1}\right)\end{array}$ & $\begin{array}{c}\rho_{1} \\
\left(\mathrm{~kg} \mathrm{~m}^{-3}\right)\end{array}$ & $\begin{array}{c}\rho_{\mathrm{v}} \\
\left(\mathrm{kg} \mathrm{m}^{-3}\right)\end{array}$ & $\begin{array}{c}i_{\mathrm{fg}} \\
\mathrm{OR} i_{\mathrm{fg}} \\
\left(\mathrm{kJ} \mathrm{kg}^{-1}\right)\end{array}$ & $\begin{array}{c}C_{\mathrm{pl}} \\
\left({\left.\mathrm{k} k \mathrm{~kg}-1 \mathrm{~K}^{-1}\right)}\right)\end{array}$ \\
\hline Oleic acid & 278.55 & $1.9 \times 10^{-6}$ & 219.0 & 224.0 & 24000.0 & 0.033 & 892.0 & $(-)$ & 140.20 & 2.046 \\
\hline $\begin{array}{l}\text { Octanoic } \\
\text { acid }\end{array}$ & 289.25 & $2.5 \times 10^{-4}$ & 105.4 & 147.0 & 7500.0 & 0.039 & 910.0 & $(-)$ & 148.59 & 2.0656 \\
\hline R410A & 282.0 & 1048.4 & 2.3 & 98.2 & 144.81 & 0.007 & 1133.3 & 40.45 & 210.04 & 1.5710 \\
\hline
\end{tabular}

${ }^{4}$ Obtained from REFPROP 10.0 while using the default equations (Lemmon et al., 2018) 


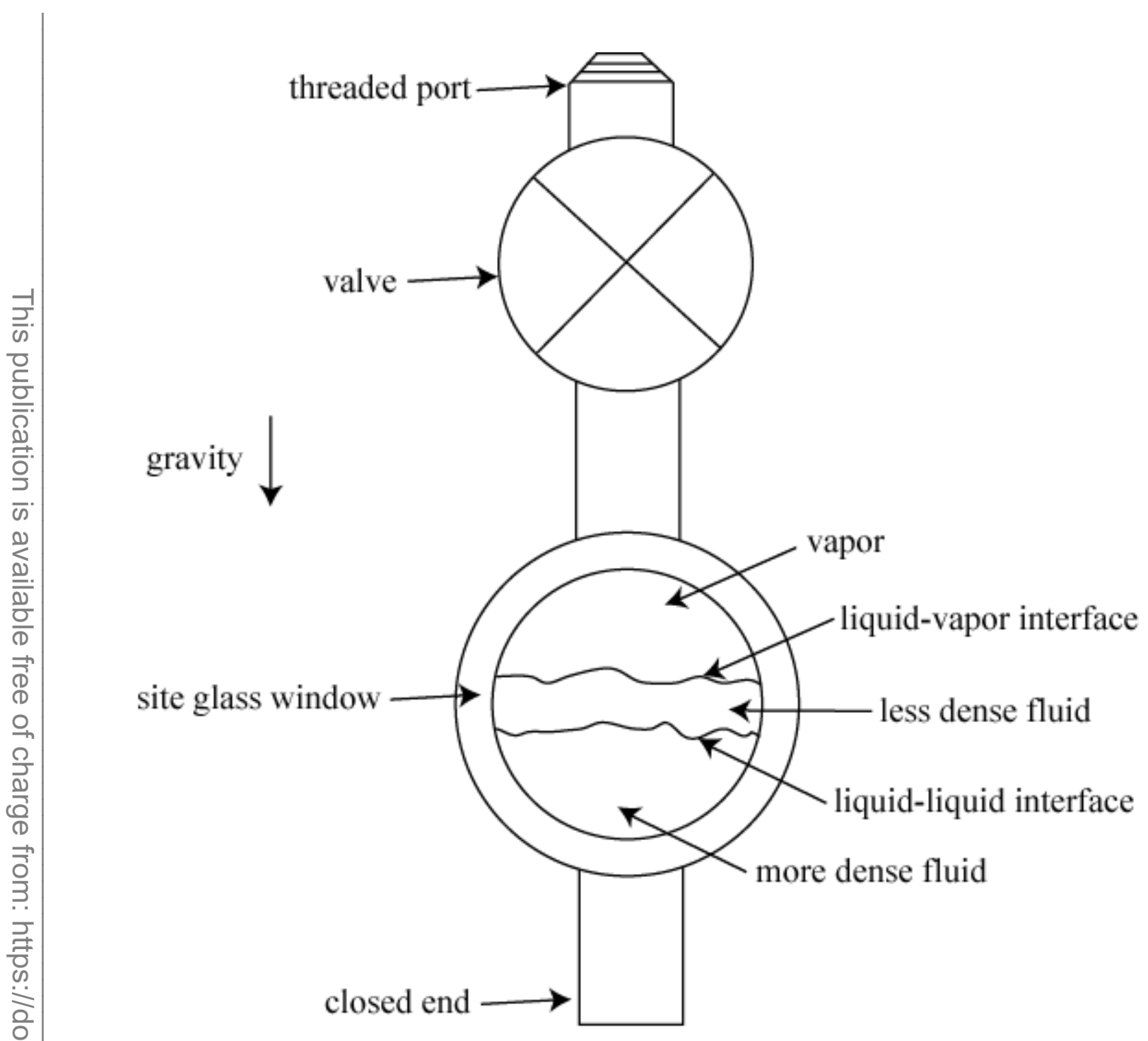

Figure 1 Schematic of pressure vessel to observe miscibility 


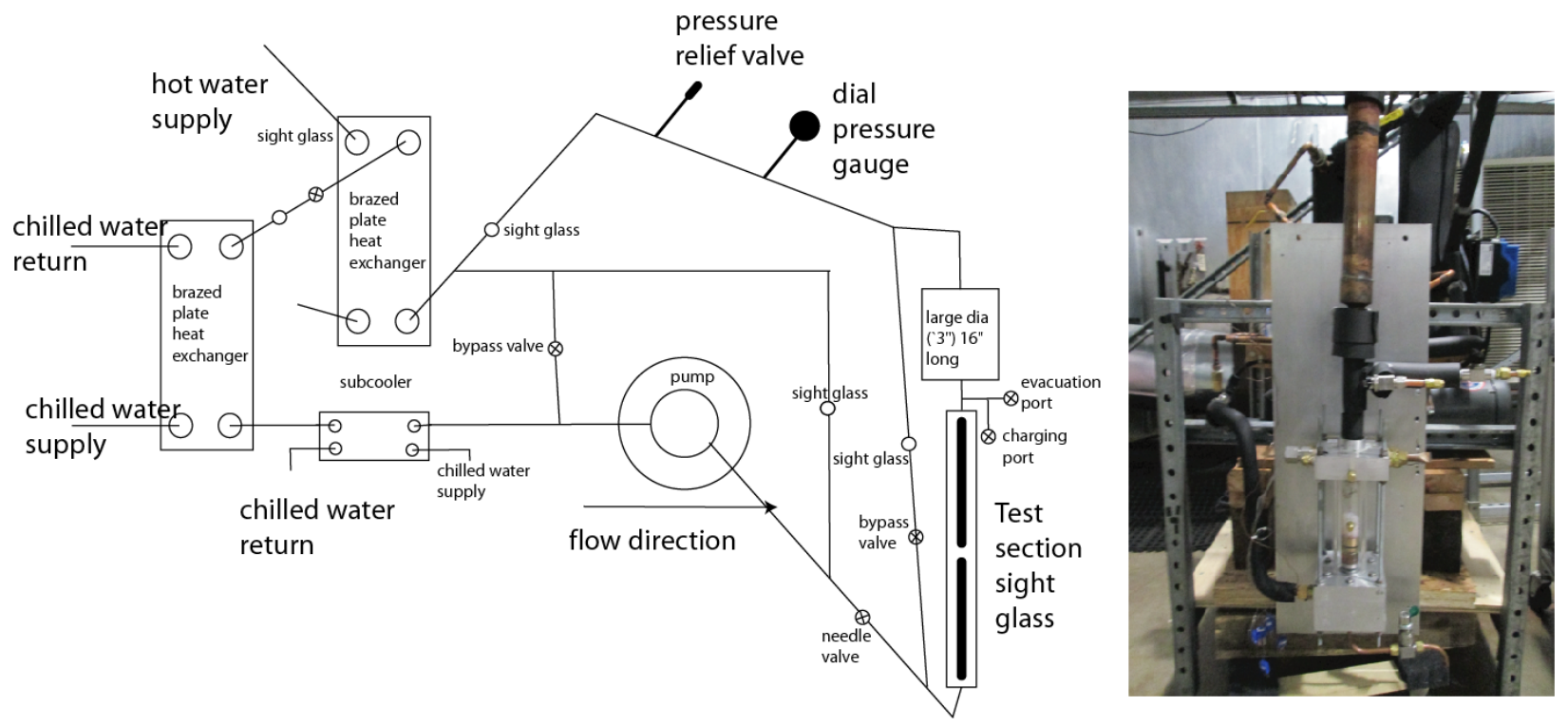

Figure 2 Schematic and photo of PCM/refrigerant flow observation test apparatus 


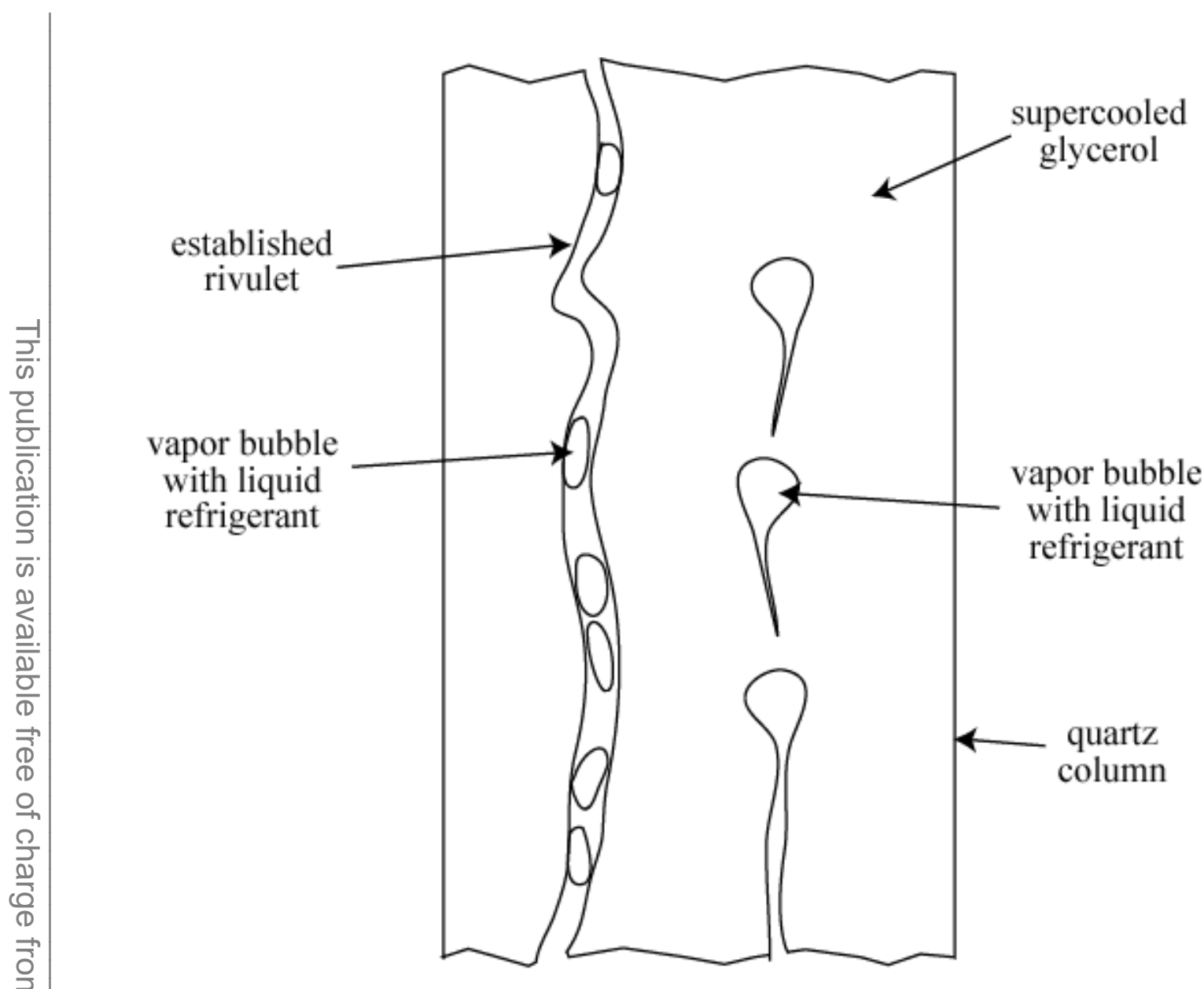

Figure 3 Primary flow patterns for evaporating R134a rising through glycerol 


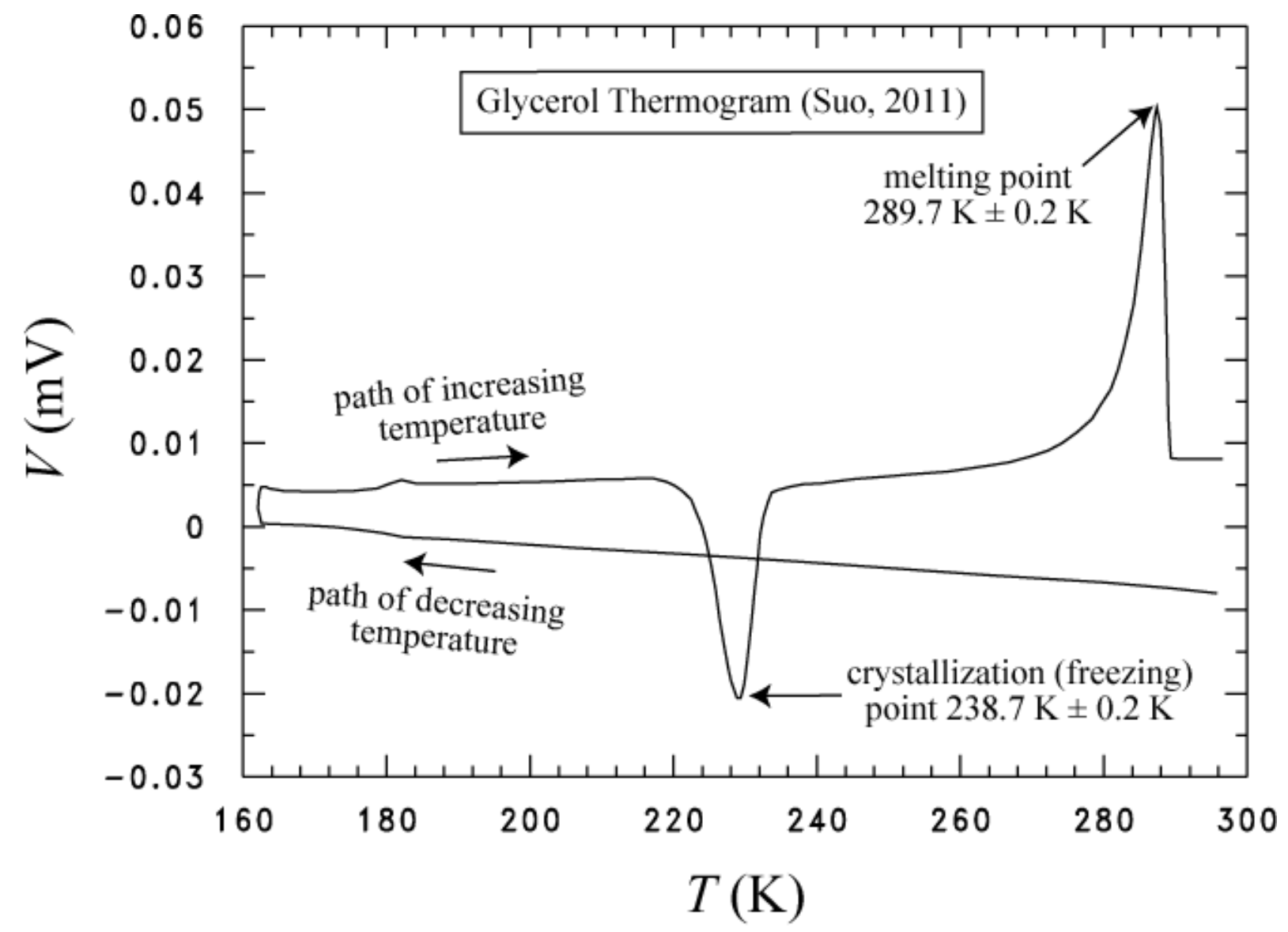

Figure 4 Glycerol thermogram (Sou, 2011) 


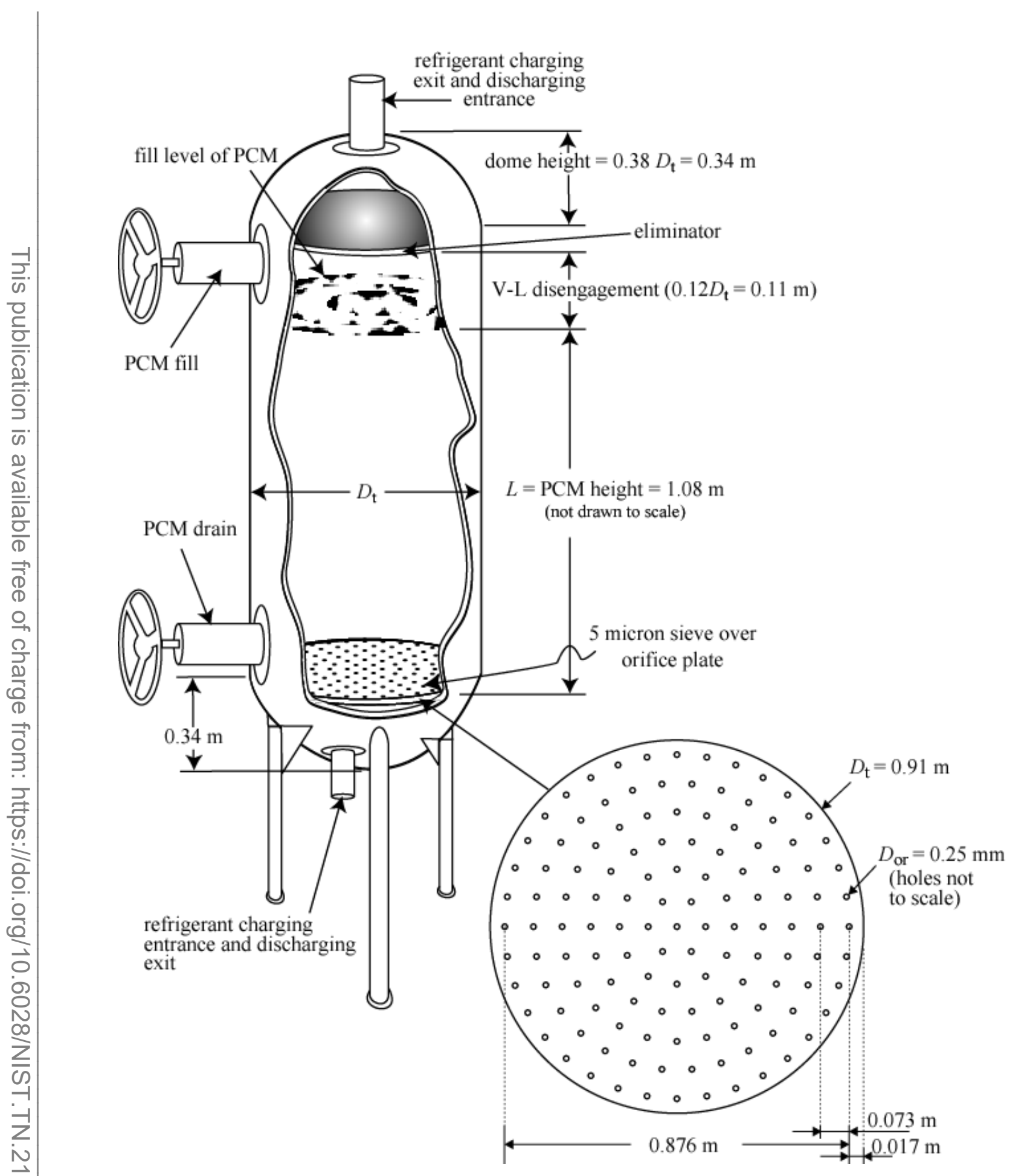

Figure 5 Direct-contact heat exchanger designed for PCM and refrigerant 


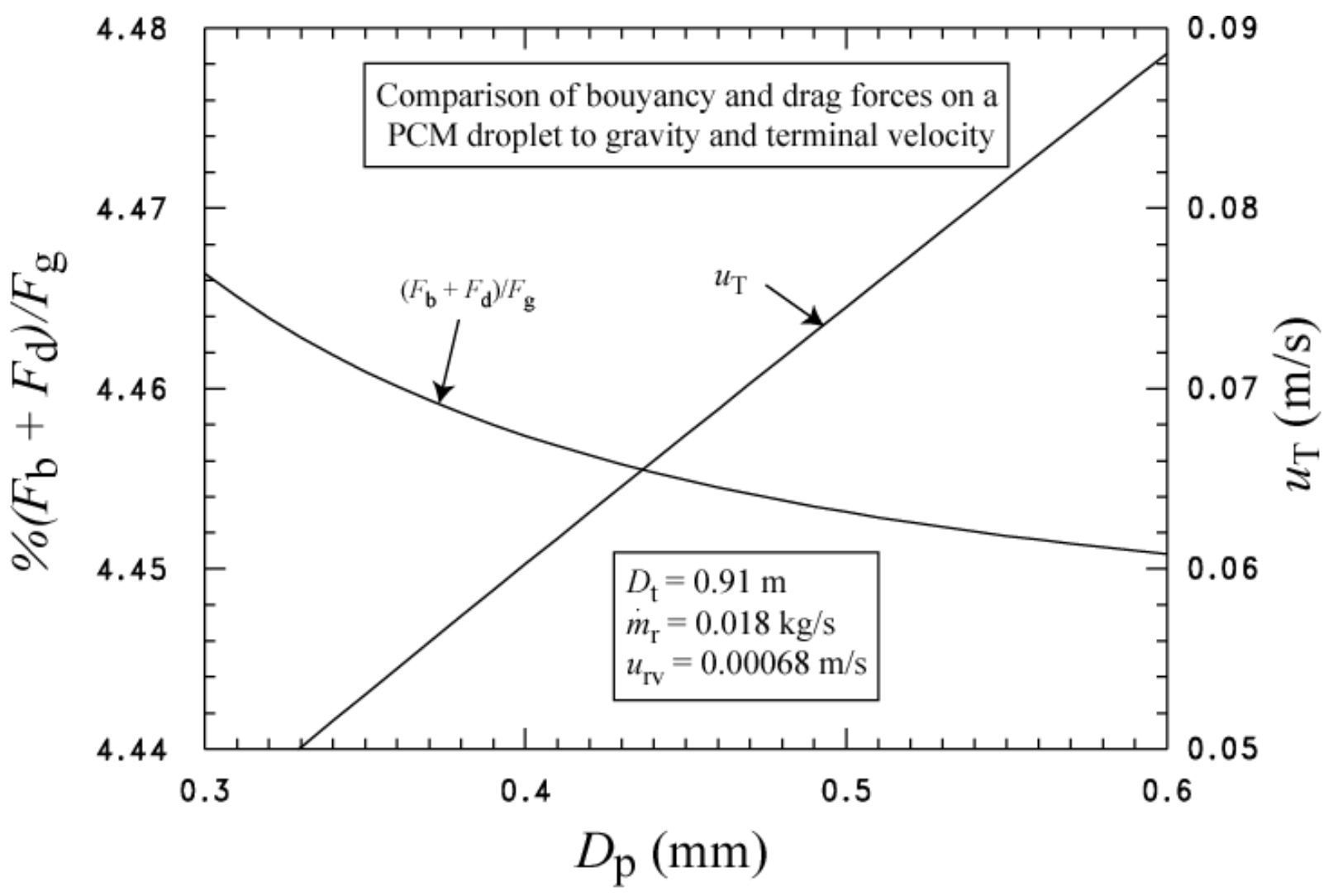

Figure 6 Comparison of measured buoyancy and drag forces on a PCM droplet to gravity as a function of droplet size and terminal velocity 


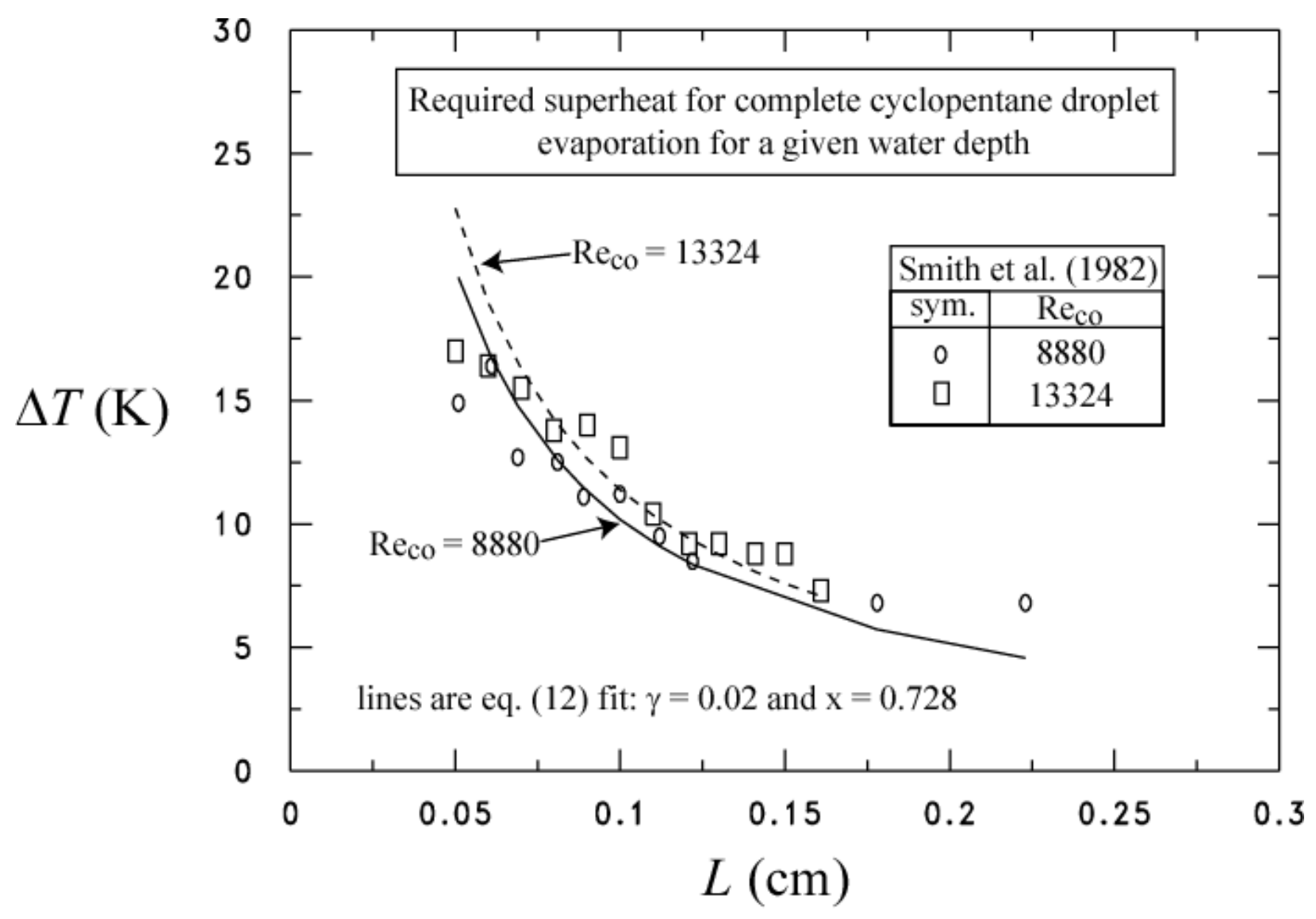

Figure 7 Required superheat for complete cyclopentane droplet evaporation for a given water depth (measurements from Smith et al. (1982)) 


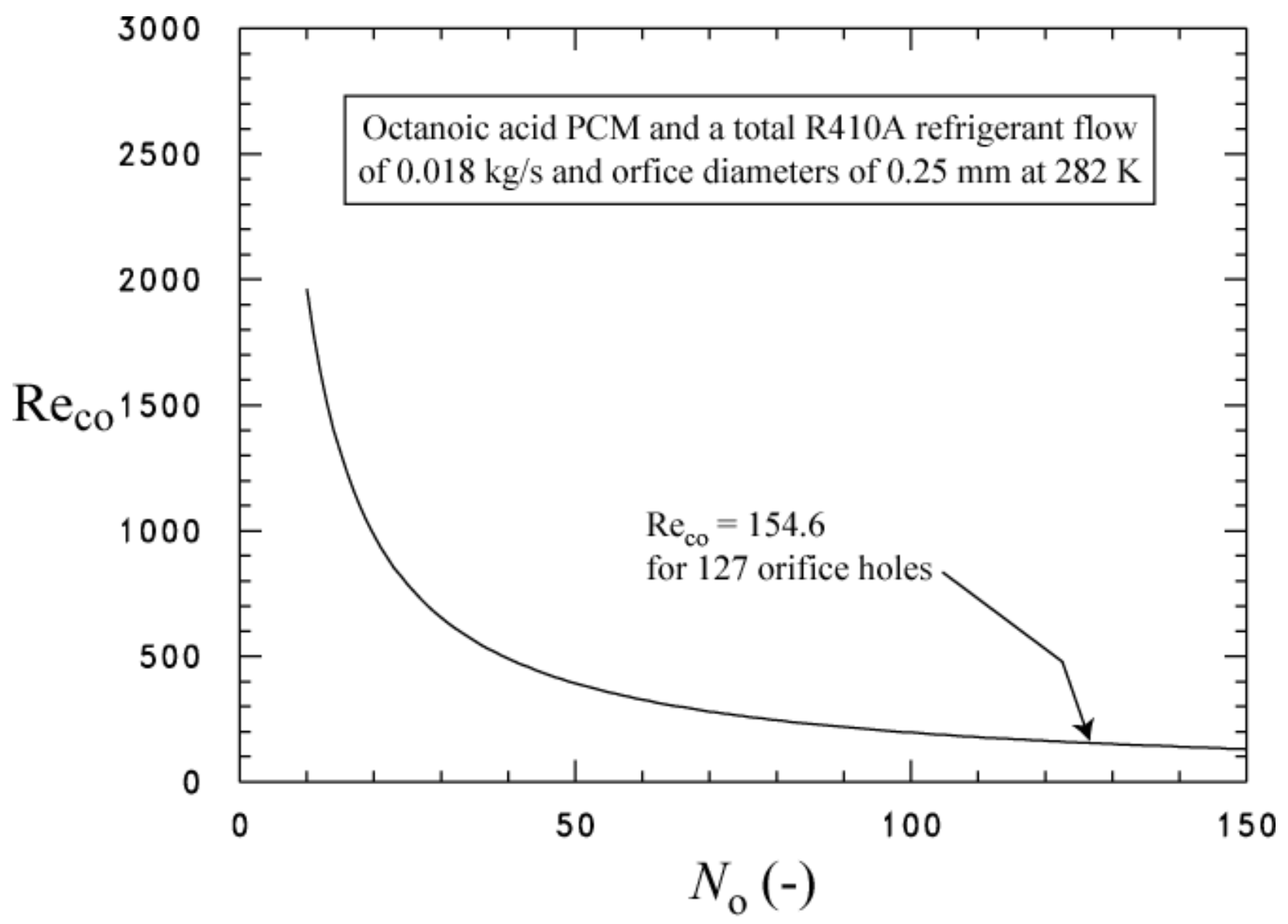

Figure 8 Refrigerant Reynolds number as a function of the number of orifices 


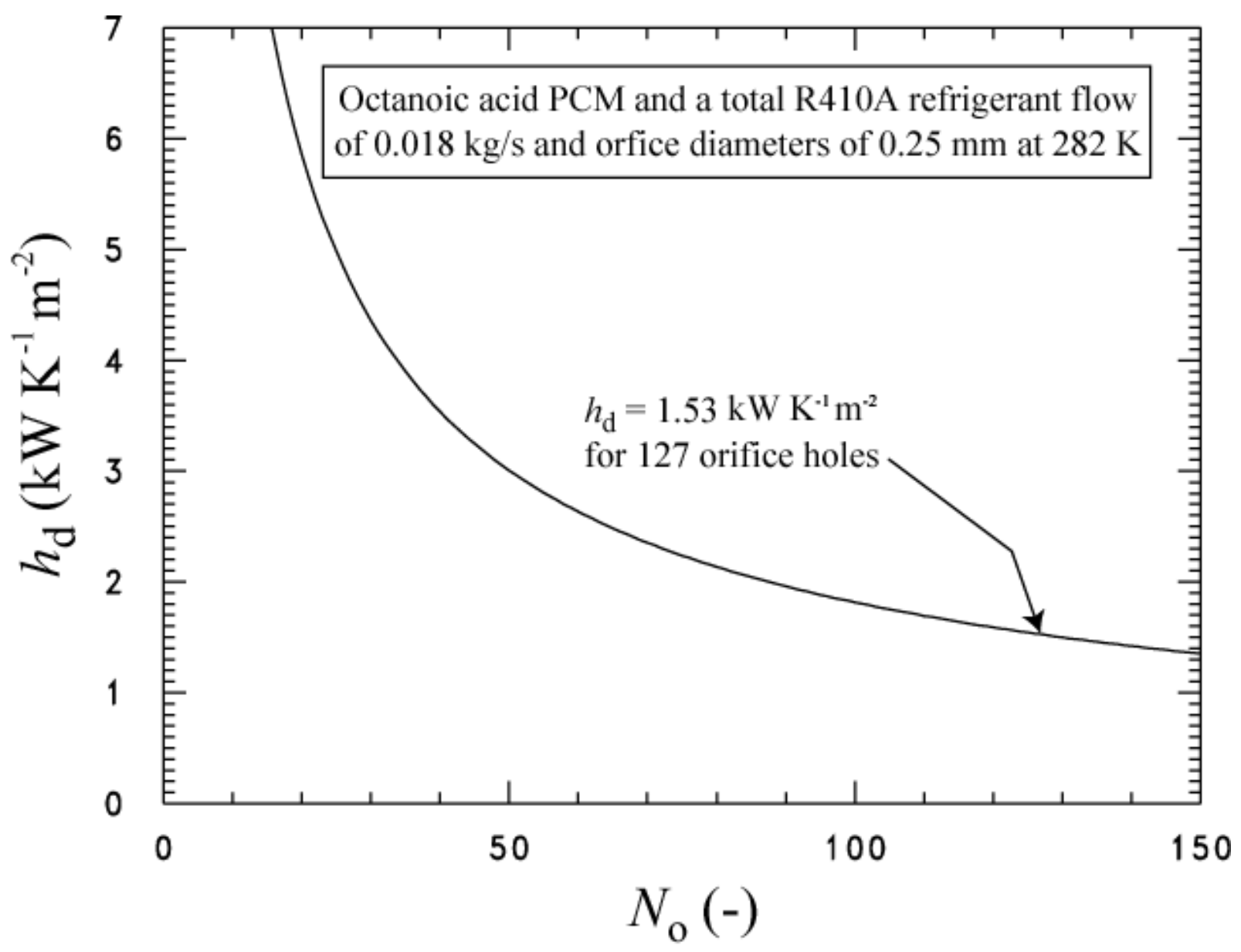

Figure 9 Droplet heat transfer coefficient as a function of the number of orifices 


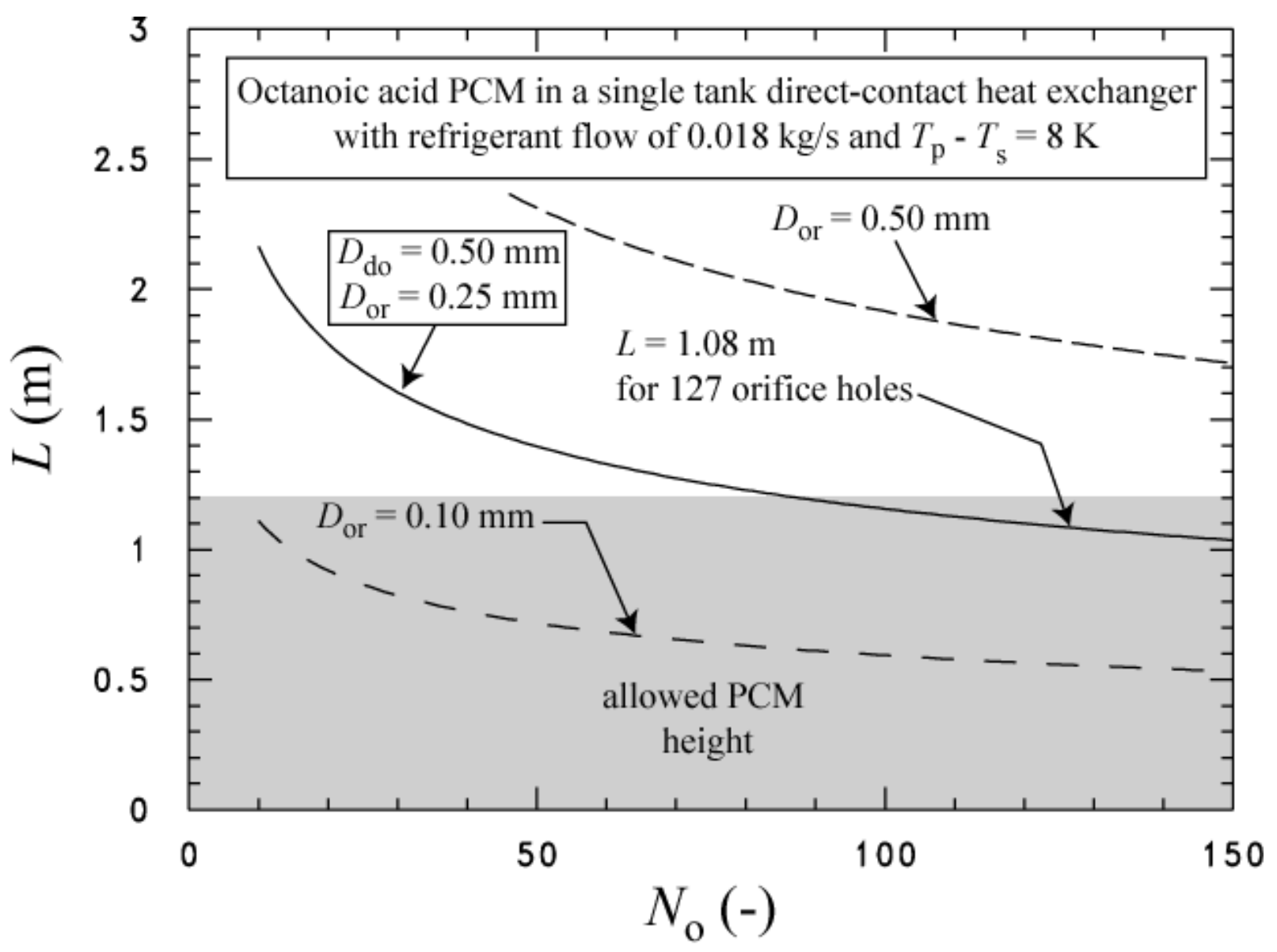

Figure 10 Height of PCM column in direct-contact heat exchanger 


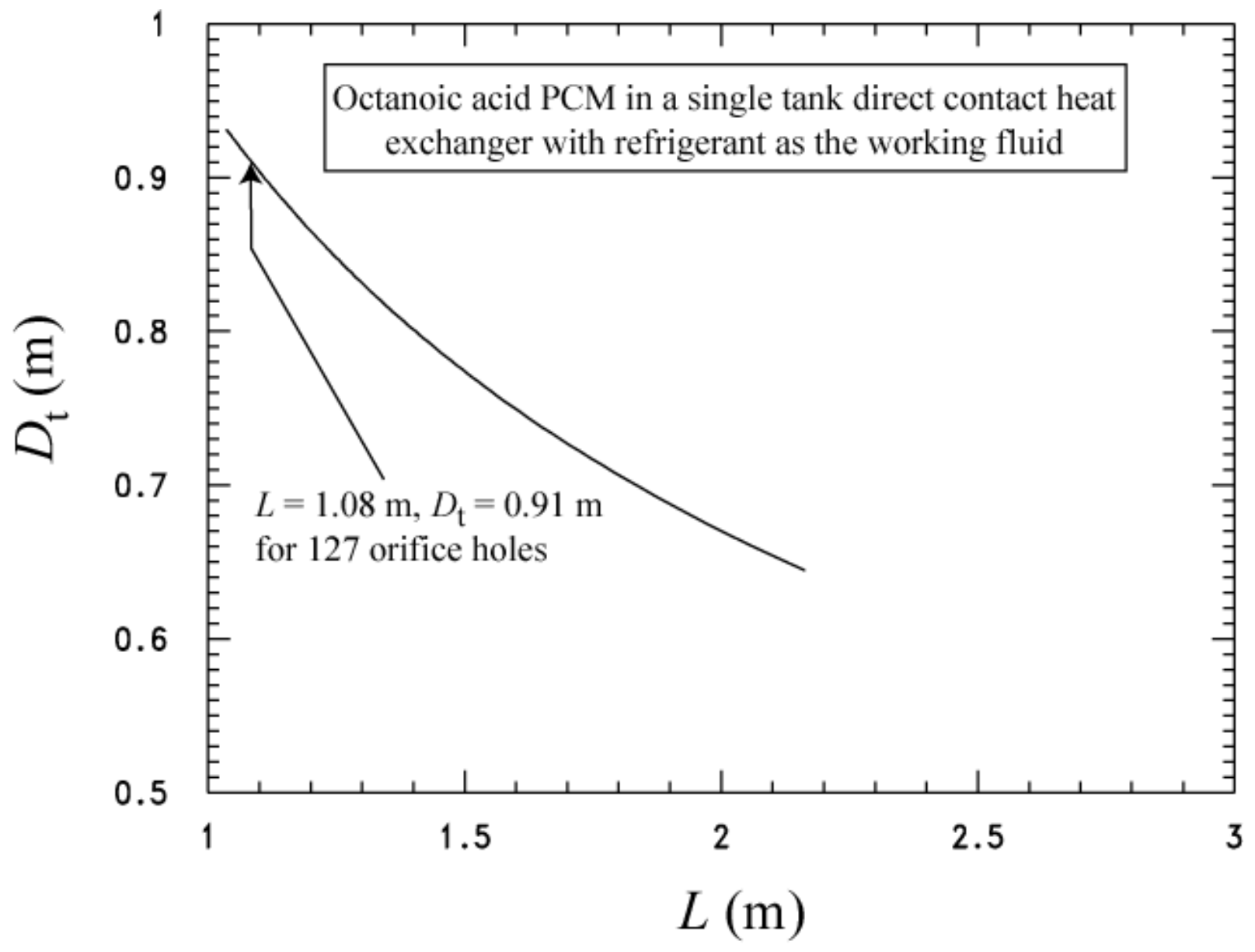

Figure 11 Diameter of direct-contact heat exchanger and a function of tank height 